\title{
DESIGNING A HISTORY MUSEUM BASED OUTREACH PROGRAM WITH DIGITAL CONTENT
}

\author{
Jacobo Moreno_uiroga [jacobo.mq@gmail.com],DaewoongKim [dwkim@design.kyushu-u.ac.jp], \\ Kyushu University, Japan
}

\begin{abstract}
This study expands on the concept of outreach programs: museum initiatives that look for ways to reach and share knowledge outside their installations, often to schools. We aim to study approaches for the development of content for a history museum outreach program using digital technologies. The significance of this lies in investigating ways to bring the knowledge of the museum to schools that cannot have easy access to them.
\end{abstract}

Three different content approaches were developed and tested. The first was an Assemblable walls exhibition, consisting of a modular structure in which three different exhibition methods were presented: object, video and interactive. Second, was a Hands-on interactive exhibition, consisting of a portable system that includes digital and analogue activities in an application developed for a smart projector. Lastly, the third approach was an interactive experience, which incorporated the various approaches tested previously and expanded upon them.

In our conclusions, we stress the significance of this research regarding offering museum content to schools without easy access and offer a list of suggestions based on our findings that museum curators could follow when considering the development of an outreach program with digital content.

\section{Abstract in Spanish}

Este estudio busca ampliar el concepto de programas de outreach; iniciativas llevadas a cabo por museos que buscan formas de compartir sus conocimientos por fuera de sus instalaciones, usualmente dirigidos a escuelas. Nuestro objetivo es estudiar aproximaciones para el desarrollo de contenido para un programa de outreach basado en un museo de historia utilizando tecnologías digitales. El significado de esto radica en investigar formas de llevar el conocimiento del museo a escuelas que no pueden acceder fácilmente a ellos.

Se desarrollaron y probaron tres aproximaciones. La primera es una exhibición de paredes ensamblables, la cual consiste en una estructura modular en la que se presentaron tres métodos de exhibición: objeto, video e interactivo. La segunda, es una exposición interactiva práctica, la cual consiste en un sistema portátil que incluye actividades digitales y analógicas en una aplicación desarrollada para un proyector inteligente. Finalmente, la tercera aproximación fue una experiencia interactiva, que incorpora los enfoques probados anteriormente y los amplía.

En nuestras conclusiones, destacamos la importancia de esta investigación en cuanto a ofrecer contenido de museos a escuelas con dificultad de acceso y ofrecemos una lista de sugerencias basadas en nuestros hallazgos que los curadores de museos podrían seguir al considerar el desarrollo de un programa de outreach con contenido digital.

Keywords: outreach programs, digital content, museum education 


\section{Introduction}

Museums are places for amusement (Aoki, 1997), without providing recreation, museums would not be a desired space for a community. However, the need to entertain goes hand in hand with the duty of imparting the knowledge that the museum has accumulated through research and collection preservation. In this way, museums are a way of "informal education" (The Japan Society for Exhibition studies, 2010). Informal education expands beyond the limits of formal education as a way to learn through spaces outside of the educational system.

Museum visits as extracurricular activities are considered important parts of formal education; therefore, museums must respond to this specific audience of schoolchildren. For this reason, museums strive to satisfy students' needs both in the educational sense and in ways that provide them with interest and enjoyment towards the knowledge they find at the museum. In order to achieve this, it is necessary to carefully design compelling experiences, in collaboration with schools, which can help reach these two objectives in the form of museum exhibitions.

The above leads to a preoccupation for imparting proper ways to educate all different kinds of minds. One specific strategy to make a certain topic stand out and communicate the knowledge might not be successful for everyone.

\section{The need for variety in exhibitions}

Because of the need for museums to be open to different kinds of visitors, museums must be able to offer different approaches to teaching the knowledge they are trying to convey. Theories of multiple intelligences and learning styles have been analysed in the context of museum exhibitions, for example Gardner's seven areas of Intelligence in Caulton's work (2004), and the learning styles identified by McCarthy, mentioned by McLean (2013). Museums can be seen as an opportunity for learners who do not fit into traditional learning models used by formal education to explore knowledge through methods they could assimilate better, effectively changing their attitudes towards topics they would be resistant to before.

Museums experimenting with teaching strategies in ways that current formal educational systems couldn't because of curriculum limitations, lead to an initial movement to adopt hands-on approaches in their exhibitions (Caulton, 2004). This essentially meant that the visitors could participate in the exhibits instead of remaining passive observers.

Making the visitor a participant of the exhibit rather than a passive observer can be achieved through digital technologies. Nevertheless, it is important to remember that learning through touching real objects is still a valuable learning resource, as real objects are a unique educational component of the museum. Designing how the information is presented and how people can engage with the content is as important as the museum collection itself. Especially in our digital era, it is required to explore how new technologies and approaches can better serve the purposes of the museum.

\section{Digital technologies in museums}

With the advent of touch panel devices, and the spread of smartphones, the act of touching a screen expecting feedback became second nature to younger generations. While interactive tabletop exhibits in museums go back some years, they result relevant to our current needs, and they can attribute their success to their collaborative and open nature (Geller, 2006). The concept of a table encourages the visitors to surround the exhibit and at the same time showcases the activity; this serves as a way to bring in passers-by to participate as well. 
Digital technologies in museum exhibitions have been increasingly populating some museums even though attachment to traditional ways of exhibition remains. However, a distancing from the museum collection materials can still be found, as they still are kept away from the public. It is important to both protect collection materials and make them accessible; finding a balance in this contradiction requires effort from many parties and a thoughtful view on the end users. In order to do this, it is necessary to make significant renovations, which might be challenging for many museums.

\section{The concept of outreach program}

Outreach programs are closely connected with distance education practices, as they aim to bring educational materials from the museum to places far away from it. The main consideration being that education through handling real materials from the museum is imperative, so it is necessary to search for approaches that facilitate this end.

Returning to the benefits of museums to formal education, it is not always viable for a school to plan a trip to the nearest large-scale museum due to time and economic limitations. For this reason, there is a need for museums to reach out to schools. This has been called outreach, where museum experts travel to a school or institution with packages that contain various activities; in Japan they have been called delivery lessons (demae jugyō). These activities include valuable explanations and hands-on activities held by museum experts, but lack what digital technologies are offering in recent museum exhibitions.

On the other hand, outreach programs may be used to attract the students to the museum as visitors, this can be helpful for familiarizing the students with materials that they see in the outreach program at school and what they would discover when they explore the museum, for example in the context of an art museum (Yutaka, 2007). However, in this study we aimed to address the issue of reaching out to schools with difficulties accessing the museum. Additionally, bringing museum-like experiences to school grounds can have benefits beyond solving schedule and monetary uses, since the experience is set in a familiar environment for the students.

An outreach program that can implement digital technologies in order to offer experiences of recent museum exhibitions requires us to study the design of a portable experience that is both engaging and fulfilling for the learning process of schoolchildren. The importance of engaging in these efforts is rooted in enabling schools without easy access to museums to also benefit from their knowledge, and the museums to expand beyond their physical limits.

\section{Outreach program approaches}

Outreach programs may come in various forms. One of these is loan-kits. Loan-kits essentially aim to pack materials offered by the museum along with class-plans in order to be used freely by teachers at schools. Examples of loan-kits can be found in the Osaka Museum of Natural History and the Japanese National Museum of Ethnology (Shaku, 2018).

These kits are characterized by containing physical objects, either real or replicas, along with paper-based explanations and activities for the educators to use in class. However, two main issues we can observe in the examples above are: the prevalence of loan-kits related to natural sciences and the lack of digital content.

A majority of the loan-kit materials analysed in this study are directed towards the teaching of science and therefore, offered by science or natural history museums. Some examples of kits related to historical education can be found: using replicas of traditional clothing and objects to 
explain about cultures. However, ways to deliver ancient artifacts alongside the loan-kits are lacking.

The second issue prevalent in loan-kits is that they lack any expansion through digital content. The authors participated in a previous research project that involved addressing this issue. In the previous study, 3D printed replicas and a series of activities for tablet computers were developed for a loan-kit where communication between real objects and the digital was the main focus (Moreno, Izumoto, Kaneko, Yonemoto, \& Kim, 2016). The findings of this study served as a starting point for the current research and are discussed in the next section.

While this article focuses on an outreach program implemented in Japan, similar approaches can be considered in museums from other countries. Loan-kits as a form of outreach have been used for years now, for example, the Museum Kits at the Museum of Cycladic Art in Greece (n.d.) and the Museum in a Box kits from the Australian Museum (n.d.). In the case of the Museum of Cycladic Art, loans abroad are also contemplated. The relatively close physical distance between European countries can facilitate outreach programs that bring museum experiences to expand museums internationally. However, the examples above, as with the examples in Japan, do not make use of technological tools that could potentiate the experiences using real objects mixed with digital content.

\section{Previous research: "The human body and its movement" loan-kit}

In a previous study, a science museum loan-kit for fourth grade of elementary school was developed and tested. Sections of an elementary school science textbook referencing the human body, the bones, muscles, movement, and how it is different from animals were taken as a starting point. During this research project, we prepared materials to be used inside a classroom, which required the teacher to learn how to implement them in class (Figure 1).

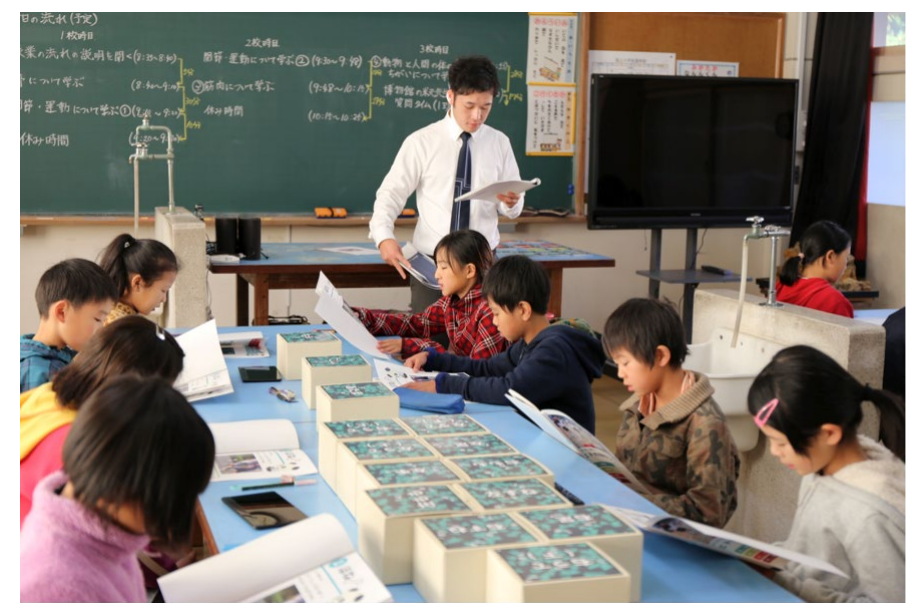

Figure 1. Loan-kit being used in class

These activities were meant to make a connection between learning about a topic through different methods that could be enhanced by digital content while also going back to interacting with real objects, which included handling replicas. It is important to note that the tablet activities always attempted to not focus entirely on the screen content but also to bring the attention of the students to real materials.

This loan-kit aimed to provide educational resources at a distance. Distance education is often associated with online resources that can be accessed through the Internet, which include bringing educators virtually to the classroom (Wellburn \& Eibd, 2016). Part of the proposed loan-kit included explanations by a museum expert that took place through a video call. In this 
case, both the museum expert and the students at the classroom had the same objects in front of them to aid in giving the necessary explanations. Thus, when the educator explained certain details about the real objects she had at her end, the students could observe similar things by handling replicas in front of them. As stated before, learning through real materials is an important part of museum education; therefore, it is important to look for approaches that enable bringing this experience to places far away from the museum. Furthermore, digital content can be used to expand the physical objects for better observation and captivating the interest of students.

The relevant findings of this previous research can be summarized in two main points:

- First, we acknowledged the importance of bringing real object handling and enhancing it through digital content, in order to not focus entirely on touch-screen interactions.

- Second, learning how to use the loan-kit materials inside a class proved challenging for the teachers. For this reason, the current research proposes an "event" approach in which instead of taking time from the school classes, the activities would take place as an event outside of class-hours.

\section{Purpose of the study}

This research project aims to study approaches for the development of an outreach program directed towards schools, that makes use of digital technologies in order to enhance the experience of the visitors both for entertainment and educational purposes. The goal is to bring part of the contents that would be found in a history museum to a school so that students can benefit from the museum's knowledge in an effective way.

We established that the program contents would be based in a history museum. As discussed above, a majority of outreach programs are primarily related to science. This tendency could be explained in part because of the difficulty that handling historical artifacts outside the museum encompasses. This research aimed to aid this problem through duplication via 3D printing. Additionally, we explored ideas to bridge the gap between digital and analogue by offering handson activities while enhancing them with digital content. We also took notes from current outreach programs in order to offer an experience in a way that could be called an "event" inside a school and different strategies were devised to attract the attention of students and encourage them to learn.

Finally, it is important to stress the significance of this research. It aims to investigate ways to bring the knowledge of the museum to schools that cannot have easy access to them. In Japan, there is a population of students in areas of difficult access such as islands far from the main land or towns deep in mountains. In these communities, schools and local culture centres fulfil the duties of educational centres. Nevertheless, they could also benefit from the knowledge of greater scale museums. Their technological advancements for transmitting information ought to be used to achieve this goal. A parallel can be made with early distance education approaches, as the objective was to bring schools to people in remote areas without easy access to them through correspondence, without the possibility of face-to-face learning (Wellburn \& Eibd, 2016). In a similar way, this research project focused on bringing the experience of museums to remote places, however in this case they are aimed at schools, so educators are already present, and would only require minimal guidance on how to use the resources provided by the museum. 


\section{Methods}

The exhibitions were developed through an iteration model, where prototypes are produced and tested according to the results obtained in their previous form. Therefore, each iteration evolves by solving previous issues, and looking to explore different topics that are considered important to address based on the researchers' observations.

We sought to test each iteration with the target audience: elementary school students. Questionnaire surveys, user behaviour observation and system logs were applied as evaluation methods in this study. It was also decided to test the application of a neurofeedback device in order to achieve an objective collection of data regarding user reactions towards different media as an additional evaluation method that would supplement the others. For this reason, a short preliminary research on neurofeedback evaluation was carried out and the devices were tested first with adults.

Below, the iterative process undertaken in this research is summarized (Figure 2).
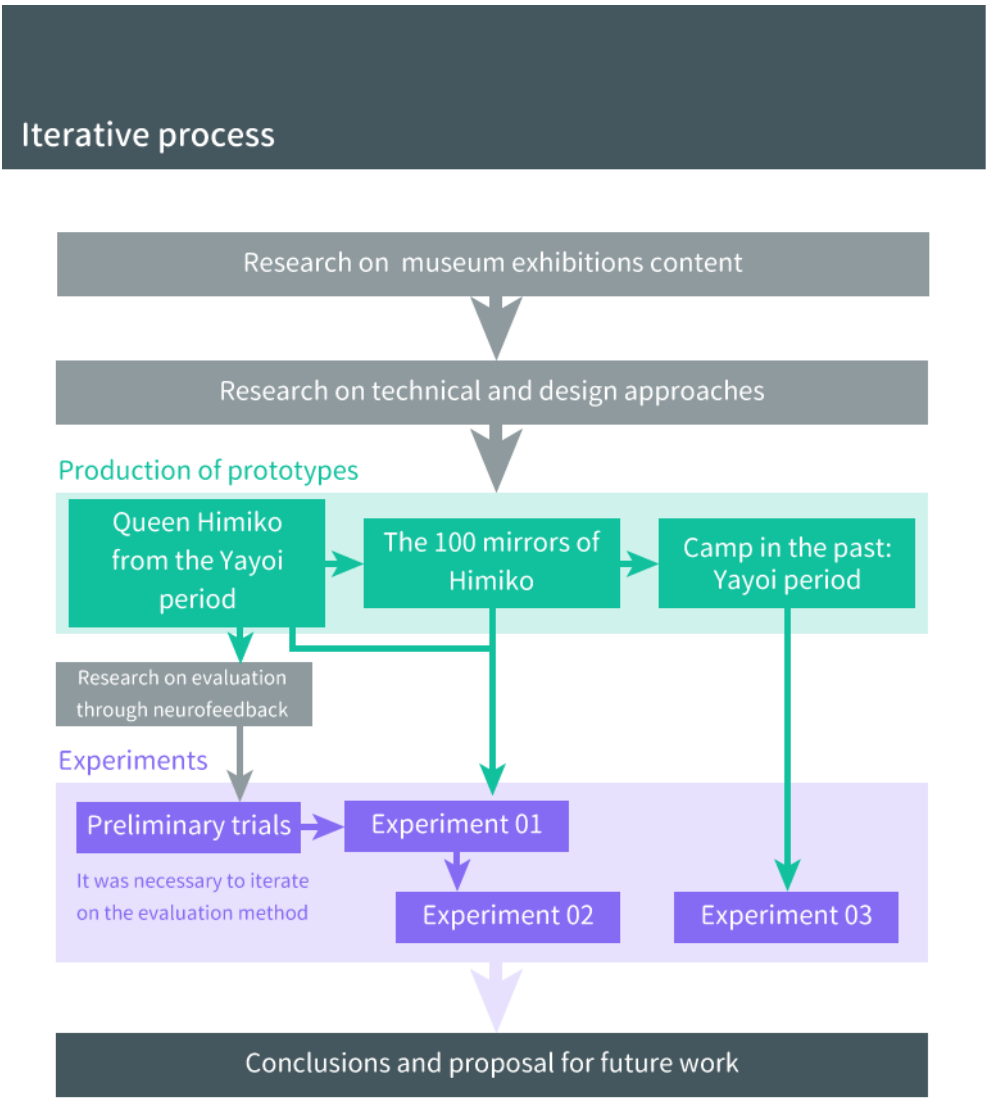

Figure 2. Iterative process

\section{About neurofeedback evaluation and analysis}

In order to include to neurofeedback evaluation in this study, the Muse headband, originally created for meditation and relaxation purposes, was utilized. A third-party application called Muse Monitor allows us to read the raw data from Muse and convert it to the most common types of brainwaves based on their frequency. Using these tools, it was possible to detect levels of Delta, Theta, Alpha, Beta and Gamma; multiple resources back up the characteristics related to each of these levels. 
For the analysis, we based our conclusions on the general descriptions and characteristics of the brainwave bandwidths as described by Demos (2005). It is important to note that the results of our experiments were observed based on these established principles, and we attempted to draw conclusions on them, not alone but in combination with other methods of evaluation. Nonetheless, we are observers, not experts on the area (Figure 3).

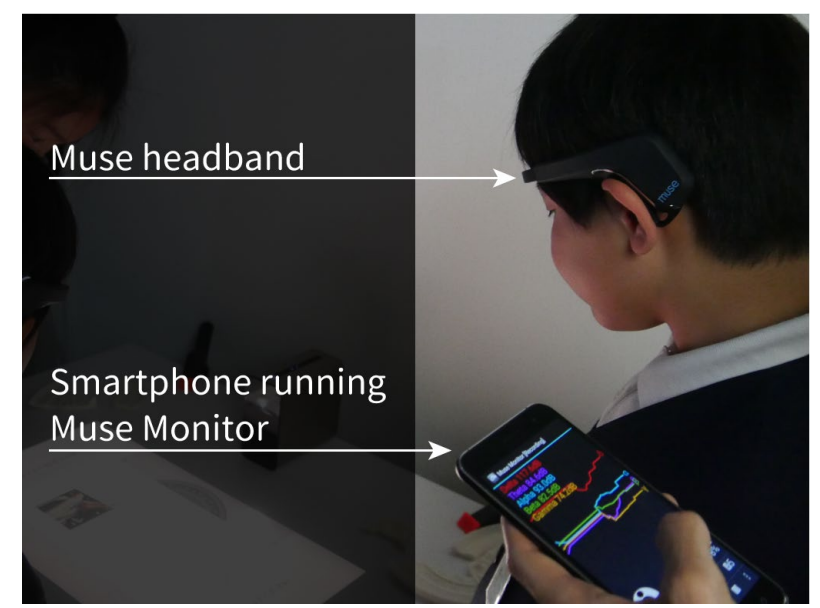

Figure 3. Using the neurofeedback device on one of the experiments participants.

This simplified EEG device was used because it enabled the experiment participants to move with relative freedom, in contrast to more advanced equipment that would limit their movement. Nevertheless, body movements affected the data in multiple instances. In these cases, the obtained results were discarded; however, the data that was obtained successfully served as supplementary information that was later used to supplement our conclusions. Lastly, regarding ethical considerations, we aimed to maintain all the data from the experiment participants as anonymous and did not indulge in any kind of analysis outside of our scope of evaluating the content developed for this study.

\section{Three approximations for an outreach program}

For the outreach program, the history curriculum topics for elementary school students were examined. The Yayoi period (300 BC-300 AD) was selected as the main framework because it is one of the first eras students encounter in lessons and it is the first one to introduce a historical figure.

The outreach program aimed to be introduced in the children's early relationship with history. For this reason, it was important to include strategies to captivate their interests. We decided to focus on creating a character based on an actual historical figure. In this case, the shamanic Queen Himiko, who united around thirty small countries to create the Yamatai Kingdom. Additionally, we selected the most representative object of Queen Himiko, the bronze mirror. This object is closely related to one of the important historical events students learn about the Yayoi period as bronze and iron objects were first introduced from the continent at this time.

While there are constant movements in historical research, we limited our sources to content directed at elementary school children by both the school curriculum and material from museums. It is important to emphasize that the proposed outreach program is not bound to a specific museum collection. 


\section{Assemblable walls exhibition: Queen Himiko from the Yayoi Period}

For the first approach, our main consideration was bringing the feeling of visiting a museum to a school, where the museum walls would be raised inside the school, and students could travel through different exhibitions. This posed a challenge in the sense of making the content portable and adaptable to different spaces depending on the school. Bringing the exploratory and open nature of a museum space in physical form to the school was a major objective for this first iteration. It was expected to have relevance for students who could not experience visiting a real museum to experience the space similar to one.

The Assemblable walls exhibition was designed with the purpose of testing three different exhibition methods commonly used in current museums. First, an object exhibit where students encountered an exhibition using traditional methods, consisting of a replica behind a glass with explanatory panels around it. Second, a video exhibit where a narrated animation was shown. Third, an interactive exhibit where students interacted with a digital character.

It was hypothesized that different exhibition methods would have different effects on the visitors, and that the order in which they are experienced might affect the whole experience. The purpose of this prototype was to investigate about the students' response towards the exhibition methods, both individually and as a whole, by changing the order in which they would experience them.

With these three exhibits we aimed to test and compare different ways of presenting information in an environment that imitates a museum exhibition, initially looking towards recreating the exploratory characteristics of a museum space.

\section{Structure}

The exhibition was conceptualized as an easy to transport and assemble structure. It consisted of modular pieces that, when assembled, formed a three-sided structure in a manner of panels each assigned to one of the exhibition methods (Figure 4). The form of a $C$ shape enabled an inner space for using a projector to show the video exhibition as a small theatre. The side panels were accompanied by stands, one that contained the replica of the object exhibit, and the other a tablet device to use along with the screen of the interactive exhibit. These were designed having the average height of our target users in mind.
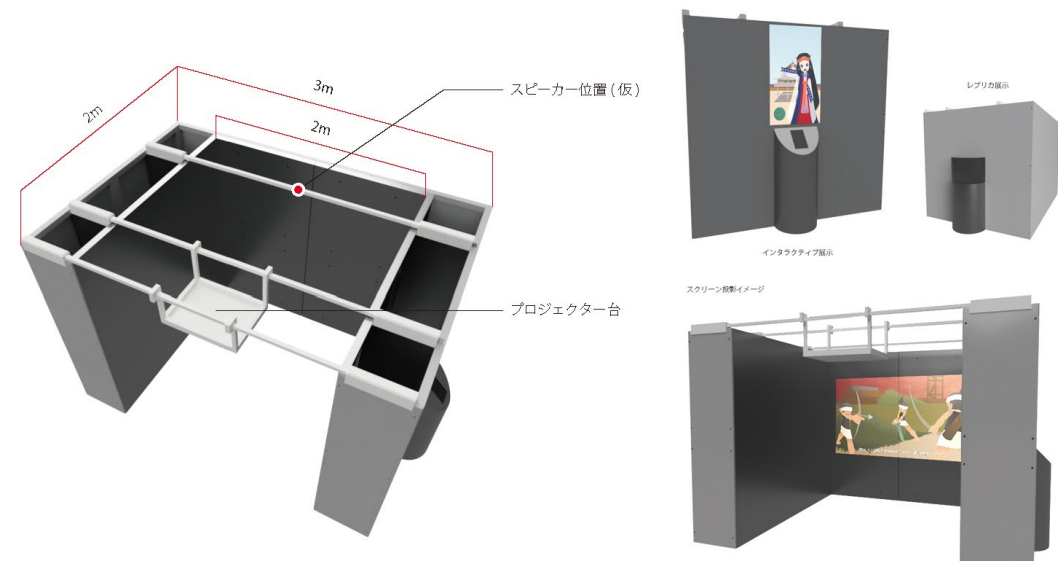

Figure 4. 3D plan of the Assemblable walls exhibition structure 


\section{The three exhibits}

In the object exhibit, a replica of a bronze mirror was shown behind a glass with explanation panels surrounding it (Figure 5). The main objective of the object exhibit was to test the most traditional way of museum exhibition; nevertheless, it was planned for our target audience. Through the exhibition of a single object, children were meant to associate it to the story of Himiko, and study it through observation, which was mainly directed by a guide while experiencing the exhibition.

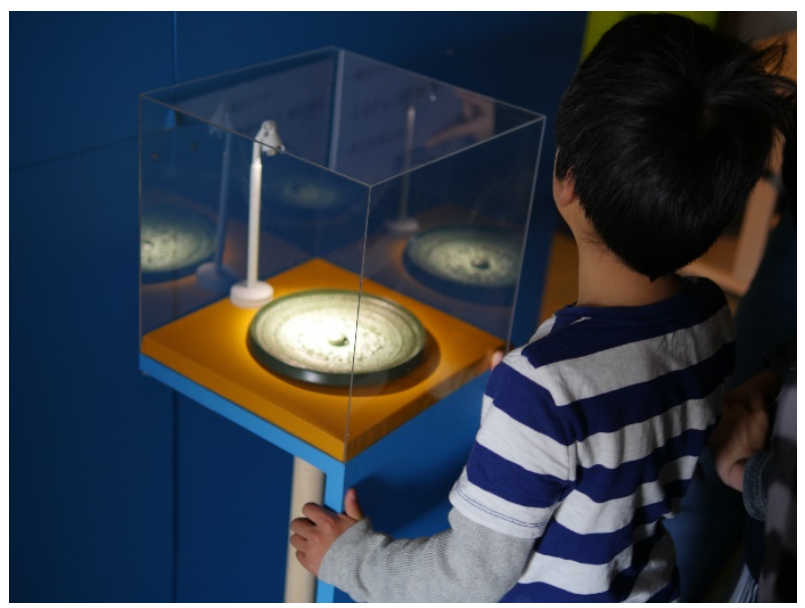

Figure 5. Bronze mirror replica

The video exhibit consisted of a one-minute animation that explained concepts related to the Yamatai Kingdom, and how Himiko unified the small countries that formed it. For the animation, we consulted depictions of Yayoi period objects in our resources and made illustrations based on them. The animation was accompanied by a narrator's voice, background music and sound effects in order to convey the different actions despite the limited animation (Figure 6).
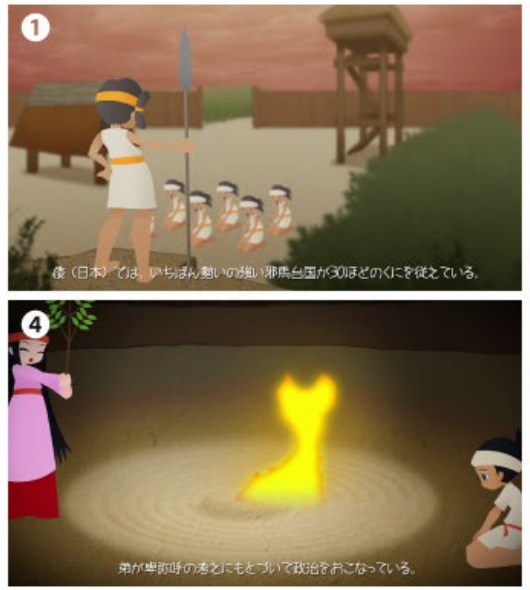
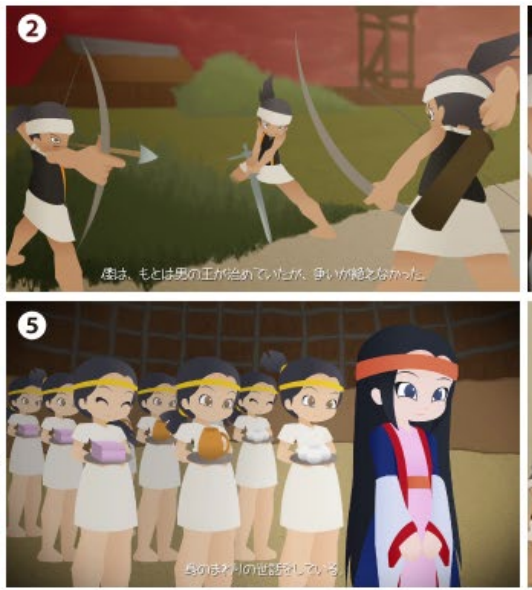

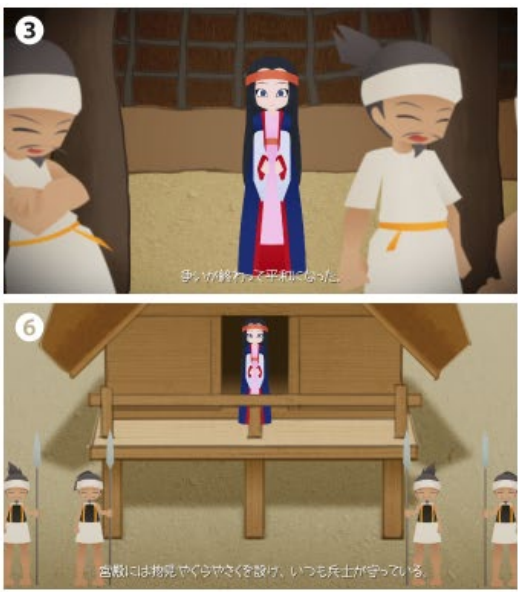

Figure 6. The six still frames of the animation

The interactive exhibit presented Himiko as an interactive character that used a voice recognition system in order to respond to specific voice commands. Students would say "keywords" related to the Yayoi Period aloud and the animated character would respond with an explanation. These keywords were selected based on the most important concepts from the Yayoi period according to our sources. Additionally, some additional words were included in order to provide the students with more interactions with Himiko. 
This exhibit used a display connected to an Android based tablet running the application made in Unity (Figure 7). A stand for the tablet was created in order to bring focus towards the Himiko on the wall and to present a simple user interface (Figure 8).

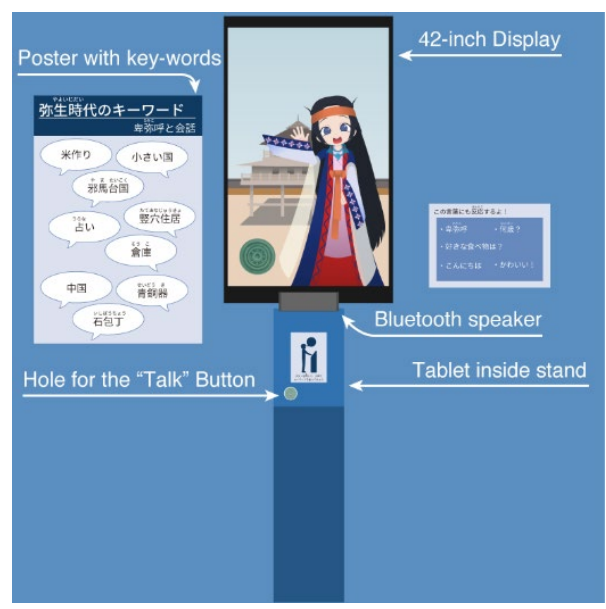

Figure 7. Organization of the interactive exhibit

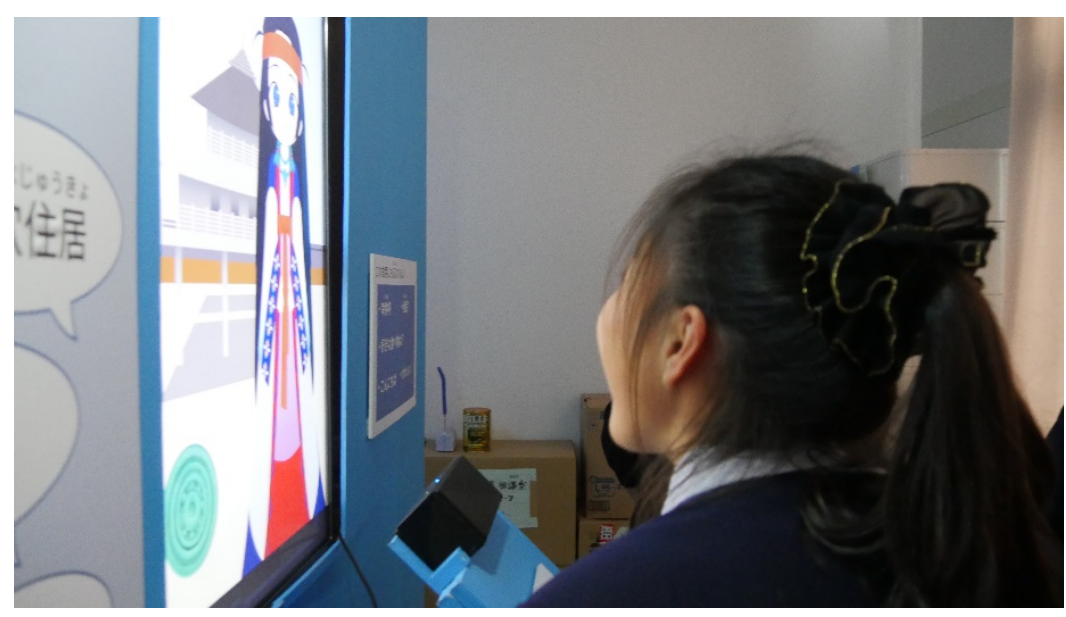

Figure 8. Interactive exhibit being used

\section{Experiments and Results}

We aimed to test the Assemblable walls exhibition in a school environment as if it was an outreach program carried out by a museum. It was decided to test both the first and second iterations of the outreach program simultaneously. Consequently, the experiments explained below share some similarities with how the second iteration was tested. The process regarding the second iteration will be explained in its corresponding section.

Experiment 01 and 02 objectives for the Assemblable walls exhibition were as follows:

- Observing the effects that different exhibition methods might have on the participants.

- Observing the effects that changing the order of experiencing the different exhibition methods might have.

- Evaluate the Assemblable walls exhibition in a controlled environment.

- Evaluating the Assemblable walls exhibition in the intended environment for the outreach program. 
Experiment 01 took place in a controlled environment, with 14 students ranging from second to fifth grade of elementary school. Teams of four supporters were trained in order to receive each group of students. In each team: two oversaw the neurofeedback device, another was recording video and photos, and the remaining supporter took the role of the guide who helped the students through each exhibition as a guided visit in a museum (Figure 11).

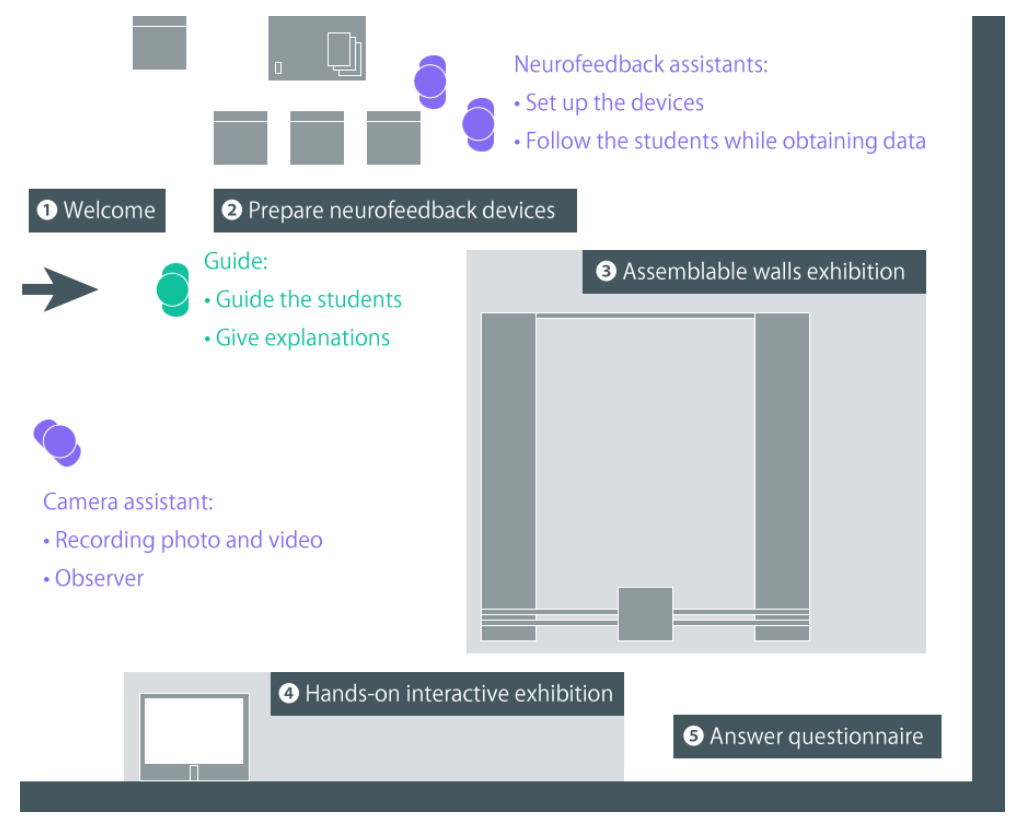

Figure 9. General layout of experiments 01 and 02

According to the surveys, the overall satisfaction scores from the Assemblable walls exhibition were high. When participants were asked to evaluate the experience with the portable exhibit overall from 1 to 5 , an average of 4.92 was achieved.

Regarding individual items in the Assemblable walls exhibition in the first experiment, the highest scored item was the interactive exhibition, and the two lowest scored items were the overall environment (lighting, walls, posters), and the museum object exhibition (Figure 10). In the open comments section of the survey and conversations, we found that some of the students felt that the exhibition was too dark, which explains the low environment score. Regarding testing the different orders for experiencing the three exhibits; significant differences could not be observed.

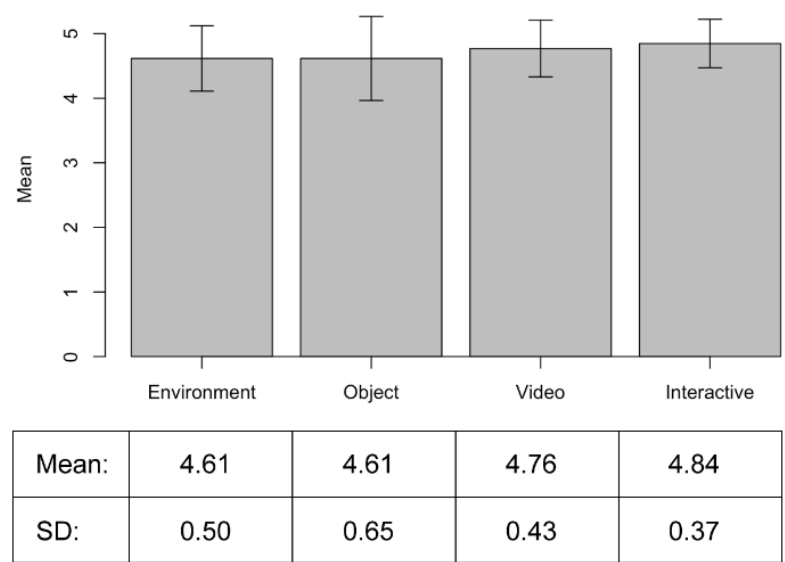

Figure 10. Mean and Standard deviation (SD) for each item in the Assemblable walls exhibition in experiment 01. 
Only the brainwave data from one student was processed correctly. Consequently, the neurofeedback evaluation from Experiment 01 only served as an exercise to define best practices.

Experiment 02 took place at the Hamasaki Elementary School in the city of Karatsu with 27 students from the sixth grade. The process was similar to the previous experiment, the difference being that in this case the exhibitions were tested with groups of students in the course of five days. The students experienced the exhibition during scheduled free time at school. Additionally, in this case all the elements for the exhibit were transported and stored at the school for the duration of the experiments.

From the surveys, it was possible to gather that the overall satisfaction scores from the Assemblable walls exhibition were high. In a question asking participants to evaluate the experience with the portable exhibit overall from 1 to 5, an average of 4.92 was achieved, the same result as the previous experiment.

Regarding individual items, the highest scored item was once again the interactive exhibition. However, this time the lowest scored item was the Video Exhibition (Figure 11).

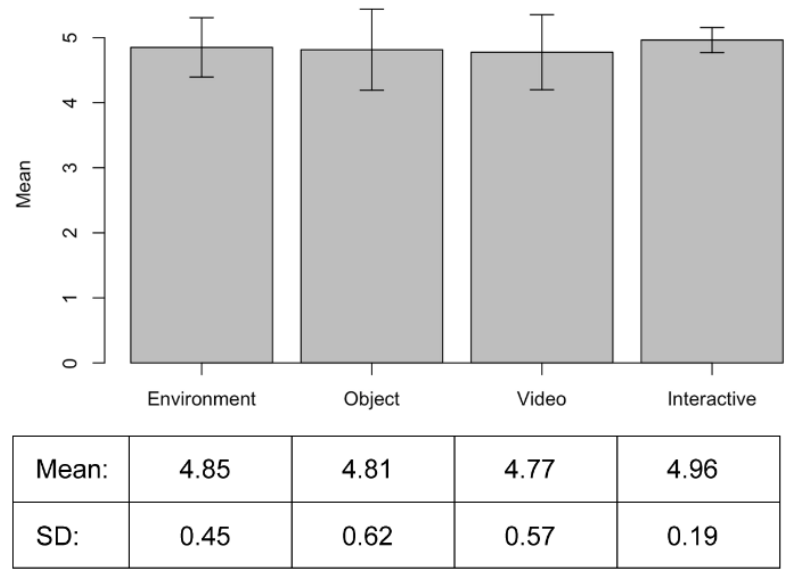

Figure 11. Mean and Standard deviation (SD) for each item in the Assemblable walls exhibition in experiment 02 .

In comparison to the first experiment, similar results for the video and interactive exhibitions were observed, with the difference that the environment and object exhibitions satisfaction level increased.

The results of the environment from experiment 01 and 02 were found to be significantly different (chi-square test, $\mathrm{P}=0.026$ ). In the first experiment $64 \%$ of students gave the environment the maximum score of 5, while in the second experiment it was $89 \%$.

A possible explanation for this difference would be that the elementary school classroom did not have a completely dark environment as was initially planned. However, another factor that can be taken into consideration is that in the case of the second experiment, the students were at a familiar place. Having the experience offered in this manner might be beneficial for the students since they do not feel the stress and uncertainty of visiting a new place, which can be considered as a positive point for effectuating the outreach program.

A $\log$ of the most used keywords in the Interactive exhibit was taken; this was an automatically generated text file that stored the most used voice inputs of the users (Table 1). From these results, we observed that students looked for activities that had an extra value beyond explanations; also, they showed an interest in the background of the character we developed. 
Table 1: Most used keywords in the interactive exhibition

\begin{tabular}{lr}
\hline Uranai (Divination) & $21.5 \%$ \\
Nan-sai? (How old are you?) & $15.6 \%$ \\
Tateana jūkyo (Pit dwellings) & $9.8 \%$ \\
Sukinatabemono wa? (What is your favourite food?) & $9.8 \%$ \\
Chūgoku (China) & $7.8 \%$ \\
Seidōki (Bronze wares) & $7.8 \%$ \\
Kawaī! (You are cute!) & $7.8 \%$ \\
Kometsukuri (Rice Production) & $5.8 \%$ \\
Chīsai kuni (Small Countries) & $3.9 \%$ \\
Kon'nichiwa (Hello) & $3.9 \%$ \\
Sōko (Warehouse) & $1.9 \%$ \\
Ishibōchō Stone knife & $1.9 \%$ \\
Himiko & $1.9 \%$ \\
\hline
\end{tabular}

Regarding the neurofeedback device, data from a total of 18 students was collected, from which 10 could be processed correctly; meaning that there were no major interruptions in the data flow during the three exhibits.

The averages of the brainwaves for each stimulus were compared and it could be observed that even in the same conditions, students had different values between them. For example, the following are graphs representing the data of two students in the same group (Figures 12 and 13). The first had a higher Beta and Gamma in the interactive exhibition, while the second had a higher Beta and Gamma in the video exhibition.

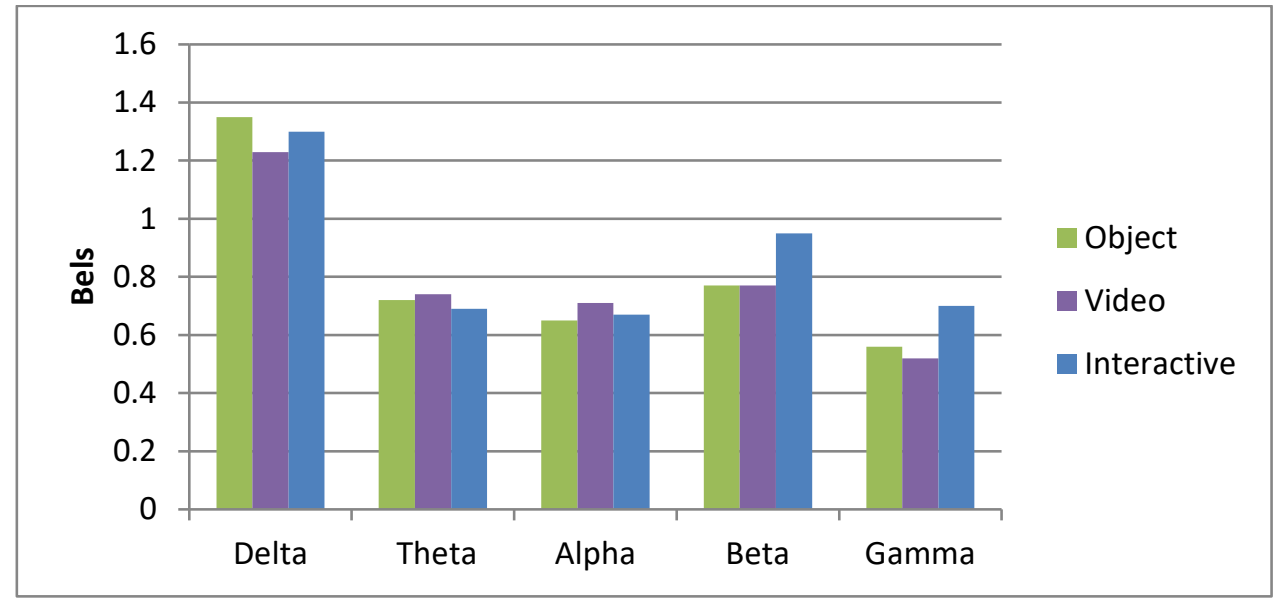

Figure 12. Average brainwave activity comparison for student 04B01 


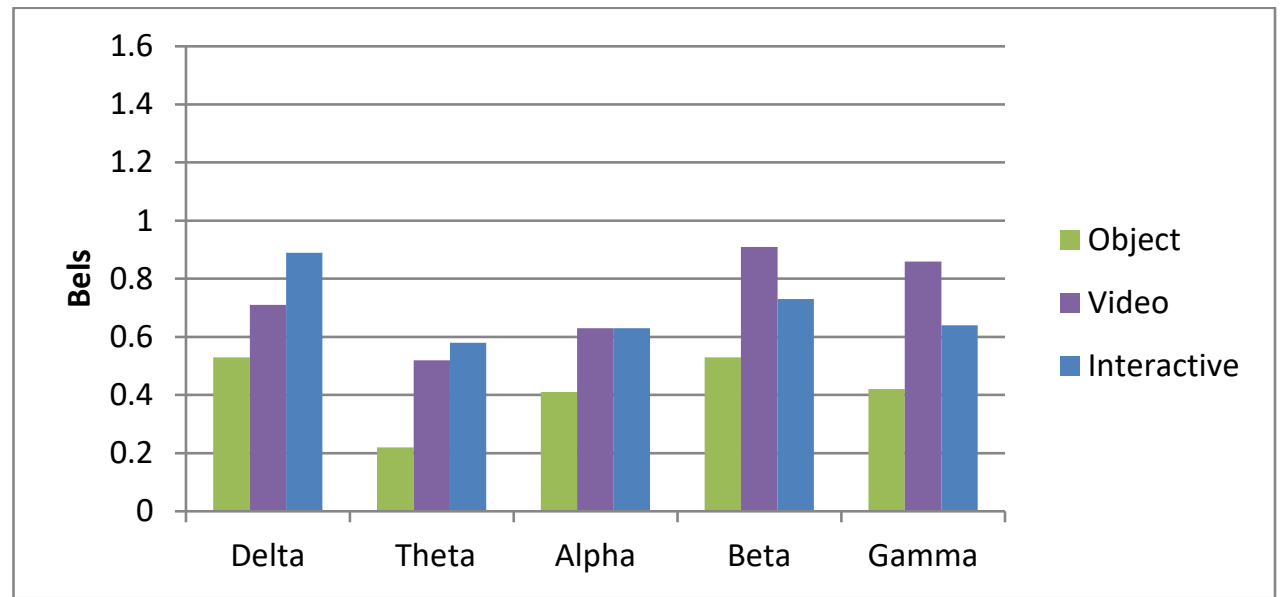

Figure 13. Average brainwave activity comparison for student $04 \mathrm{B0} 2$

In an overall comparison the greatest differences between the results are in the Gamma for interactive versus object, and in Beta for interactive versus object. Followed by the same for video versus object (Figure 14). We found a significant difference between object exhibit and interactive exhibit in Beta (paired t-test $\mathrm{P}=<<0.01$ ) and Gamma (paired t-test $\mathrm{P}=<<0.01$ ). Additionally, there was also a significant difference, in a lesser degree between object exhibit and video exhibit in Beta (paired t-test $\mathrm{P}=0.053$ ) and Gamma (paired t-test $\mathrm{P}=0.099$ ). Gamma is thought to "helps organize the brain, promote learning, and allow for mental sharpness. It is activated when the brain needs to be active and idle when no specialized task is at hand". Meanwhile Beta "has been associated with being focused, analytic, externally oriented, or in a state of relaxed thinking" (Demos, 2005). From what could be observed in this experiment, the video and interactive exhibitions promoted an increase in Gamma and Beta waves in students.

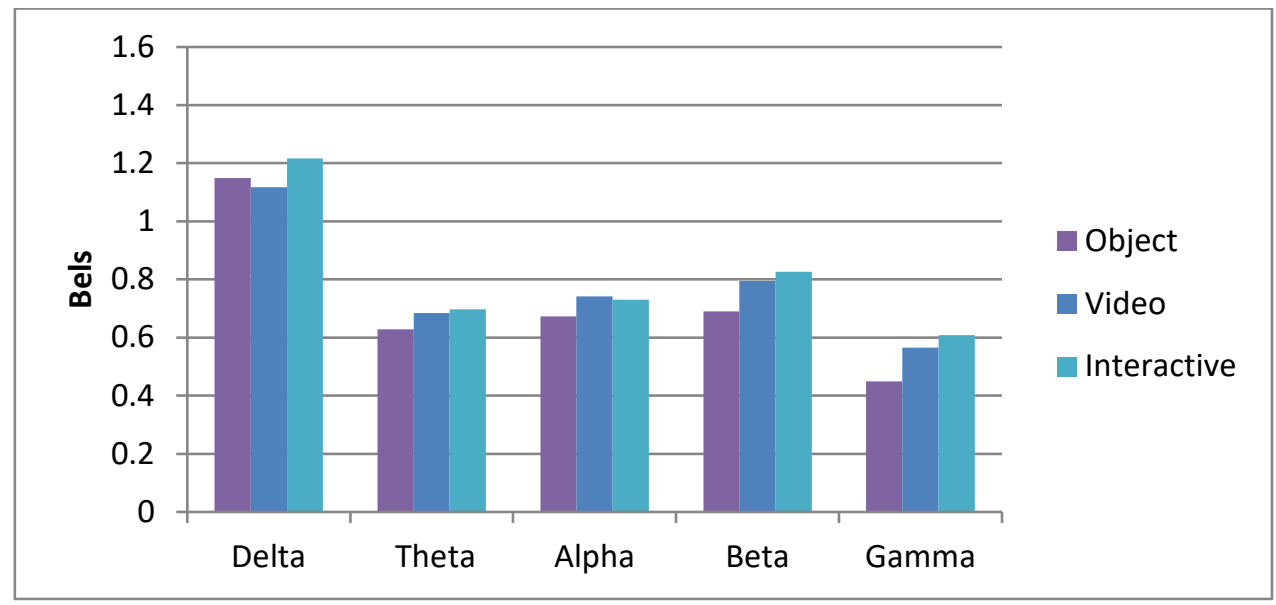

Figure 14. Average brainwave activity comparison overall.

Additionally, regarding the comparison between two students in the same group (Figures 12 and 13), this was recurrent among the students; some had greater Gamma and Beta values in video, and some in the interactive. A few students even had greater Gamma and Beta in the object exhibition. Even if the overall results show that greater emphasis should be given to interactive exhibitions, other methods should not be discarded. As discussed previously, different students have different ways of learning. 


\section{Hands-on interactive exhibition: The 100 mirrors of Himiko}

The second approach was based on observations made during the production process of the first prototype. We selected a platform that could serve as a basis for trying other exhibition methods that we were not able to test in the first prototype. In addition, an important consideration in this new iteration was to find ways to make the outreach program content more portable. The importance of doing this was to make sure the contents could be brought to the remote places it aimed to reach out.

The Hands-on interactive exhibition was conceptualized as a simpler form of content that aimed to put focus on experiencing an interactive exhibit that also included contact with a museum object replica, a form of video exhibition, and an activity that incited the students' creativity. These three concepts are directly correlated with methods for teaching through museum exhibitions: object handling, mixing real objects and digital media, and exploring creativity for learning. It was hypothesized that a creative activity would be enough for students to feel engaged with an interactive exhibit, rather than object handling or video.

Two main activities were planned, first: assemble a bronze mirror replica like a puzzle and watch a projection mapping video on top of it, and second: create your own bronze mirror digitally and take a picture of yourself to "sign it" so other people would know who made it. The main objective inside the exhibit was to create a collaborative exhibition in which each participant would make their own original mirror in order to collect all of "The 100 mirrors of Himiko", which became the name of the exhibition.

The exhibition was divided into the following steps (Figure 15): looking at a gallery of mirrors created by previous participants, assembling the replica puzzle, watching a projection mapping animation, creating an original mirror and finally, taking a picture in order to add the mirror to the gallery.

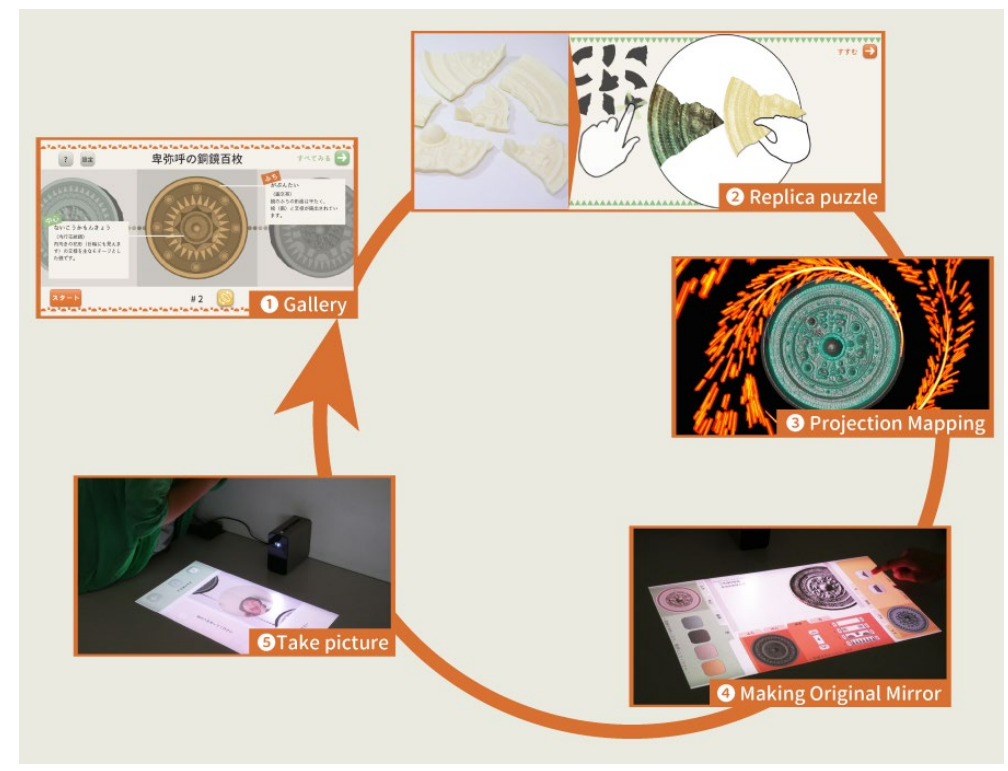

Figure 15. Main flow of the Hands-on interactive exhibition 


\section{On the smart projector}

In order to easily provide information through digital content, the following issues were considered:

- Portability, to enable us to bring the content anywhere with little effort.

- Shareability, in order to provide an experience for a group of people.

- Integration of a physical object and digital content in the same platform, to implement the activity of object handling.

In order to address the listed issues, we opted to use a smart projector. This device provided us with the opportunity to develop contents for an Android tablet with touch screen interaction but gave us some flexibility regarding the surface that the projector used.

Developing for the smart projector was done in the same way as for the interactive exhibit before: the visuals were compiled and embedded functionality through the game engine Unity, then compiled directly to Android OS. We planned an exhibit that could resemble a smart table with its characteristics of providing an interactive and shareable experience. Additionally, having a projector enabled us to cross the digital into the physical via the technique of projection mapping.

\section{$3 D$ printed mirror puzzle and projection mapping}

For the Hands-on interactive exhibition, we wanted to include the act of handling a physical object as exhibition method because of the importance of handling historical artifacts for observing and learn through them. In this case, we opted to make a replica that would be adapted for easier handling by the students, making it lighter and more resistant to damage in comparison to the replica we used in the first prototype. Additionally, some changes were made to adapt to mixing digital and physical objects; for example, making the mirror into a puzzle.

The bronze mirror replica was made based on the 3D model data of the bronze mirror excavated from Okinoshima, currently being exhibited in Munakata Taisha, in Fukuoka Prefecture (Figure 16).

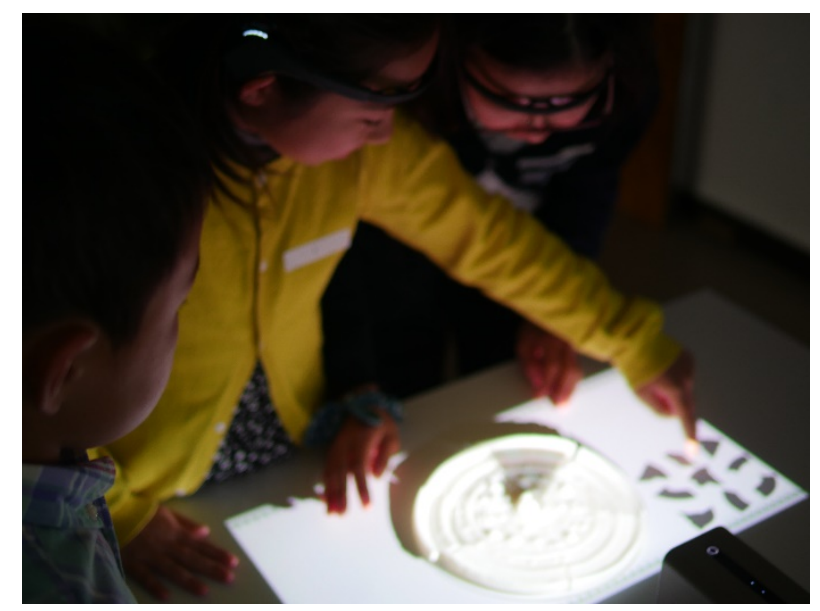

Figure 16. Replica puzzle

After assembling the mirror, the students watched an animation projected on top of the replica. The animation sequence was accompanied with cheerful music that synchronized with the movements of dancing shapes and characters. The students could more easily identify the engravings inside the mirror by watching this animation on top of the same object they just assembled (Figure 17). 


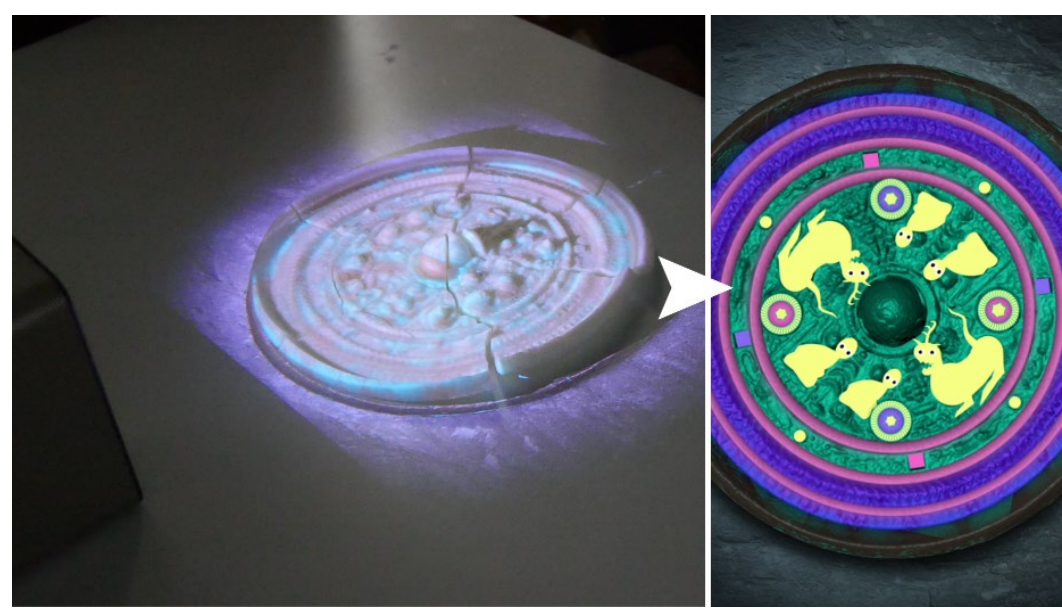

Figure 17. Projection mapping

\section{Making original mirrors}

The students proceeded to make their own original mirrors digitally by selecting various patterns taken from actual bronze mirrors, which led them to imagine how a bronze mirror could look like in a personalized experience. The UI was divided into three stations so three students could position themselves surrounding the smart projector (Figure 18).

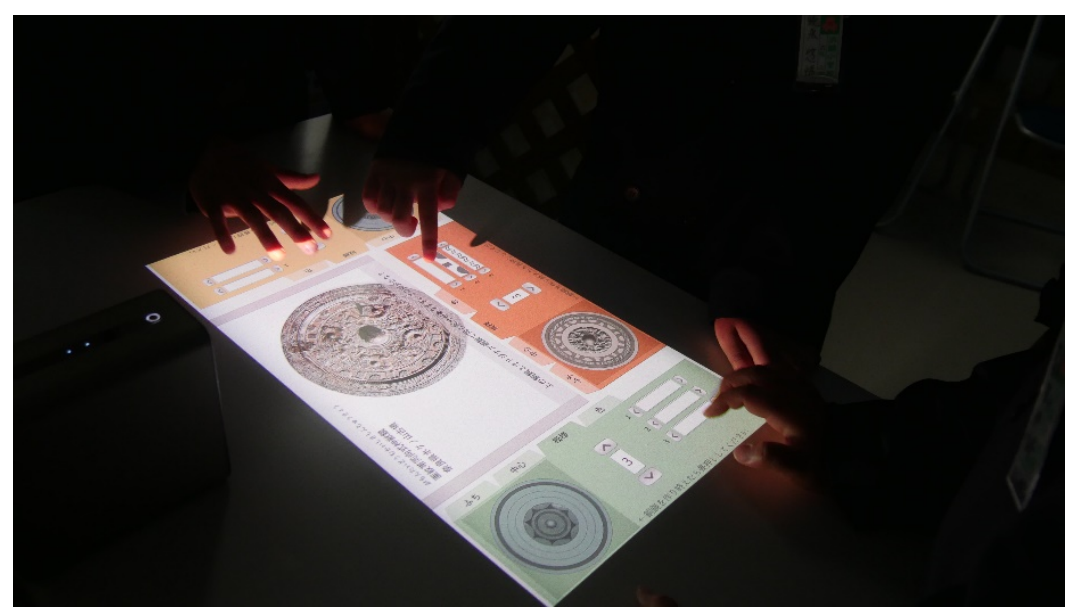

Figure 18. Three students creating their original mirrors

\section{Experiments and results}

As explained above, the experiments for the Hands-on interactive exhibition took place simultaneously with the ones for the Assemblable walls exhibition. This enabled us to make comparisons between both iterations. As with the previous iteration, two experiments took place, one with a local group and one in a school. Aside from the specifications of the experiment mentioned before, some differences were present.

Experiment 01 and 02 objectives for the Hands-on interactive exhibition were as follows:

- Observe the act of creating something in digital in comparison to other activities.

- Evaluate the Hands-on interactive exhibition in a controlled environment.

- Evaluate the Hands-on interactive exhibition in the intended environment for the outreach program.

- Evaluating the Hands-on interactive exhibition in comparison to the Assemblable walls exhibition. 
To evaluate the Hands-on interactive exhibition, the same process as the experiments of the Assemblable walls exhibition was followed, as they were done at the same time. The difference was that one of two patterns for each group of students was assigned: A, where the students looked through the replica puzzle and projection mapping, followed by the creation of their own original bronze mirror, and B where they only experienced creating an original bronze mirror. This was done in order to test whether touching and assembling the replica yielded different results with the students.

According to survey data, the overall satisfaction scores from the Hands-on interactive exhibition were high. In a question where participants were asked to evaluate the experience with the portable exhibit overall from 1 to 5 , an average of 4.92 was achieved, no different in comparison to the Assemblable walls exhibition.

In a different question, the students were asked to select which exhibition they liked more. In experiment 01, it was only divided between the Hands-on interactive exhibition and the Assemblable walls exhibition overall, here $64 \%$ answered the Hands-on interactive exhibition, and only $22 \%$, the Assemblable walls exhibition. The other $14 \%$ chose both or neither. Here we could see a preference towards the Hands-on interactive exhibition, but from other questions we could not identify differences between groups A and B, for which we had to revise the survey questions for the next experiment.

As for the neurofeedback data, the same as with the Assemblable walls exhibition, not enough data could be collected correctly.

Experiment 02 followed a similar pattern to the previous one, however in this case; it was carried out in an actual elementary school for a span of five days. The testing of the Hands-on interactive exhibition took place at the same times of the Assemblable walls exhibition. The transportation of the materials for the Hands-on interactive exhibition was done only by the team of supporters that assisted the experiment, in comparison to the transportation necessary for the Assemblable walls exhibition.

From the surveys, the overall satisfaction scores was high, in a question for evaluating the experience with the portable exhibit overall, 5 was achieved in the Hands-on interactive exhibition, slightly surpassing the Assemblable walls exhibition.

In an open question about what the students liked most about the Hands-on interactive exhibition: among students in pattern A, $71 \%$ referenced the activity of creating an original bronze mirror as their favourite and the remaining $29 \%$ preferred the projection mapping. On the other hand, among students in pattern $\mathrm{B}, 83 \%$ referenced creating an original bronze mirror as their favourite activity and the remaining $17 \%$ referenced the Chinese characters on the mirror, probably referring to what they learned throughout the object exhibit in the Assemblable walls exhibition.

It is important to note, that the students who referenced creating an original bronze mirror consistently used the words by myself and/or variations of the verb to make. These results show a strong tendency towards preference for the creative activity.

The students were asked about their favourite items in each exhibition in the form of a multiplechoice question. The overall results for common items in the A and B groups show that the activity of making an original bronze mirror was the most selected. Meanwhile, observing the bronze mirror replica in the object exhibit was the least selected; this is presented in comparison to the three exhibits from the Assemblable walls exhibition below (Figure 19). There was a significant difference between make bronze mirror and object exhibit (chi-square test $\mathrm{P}=0.035$ ). 


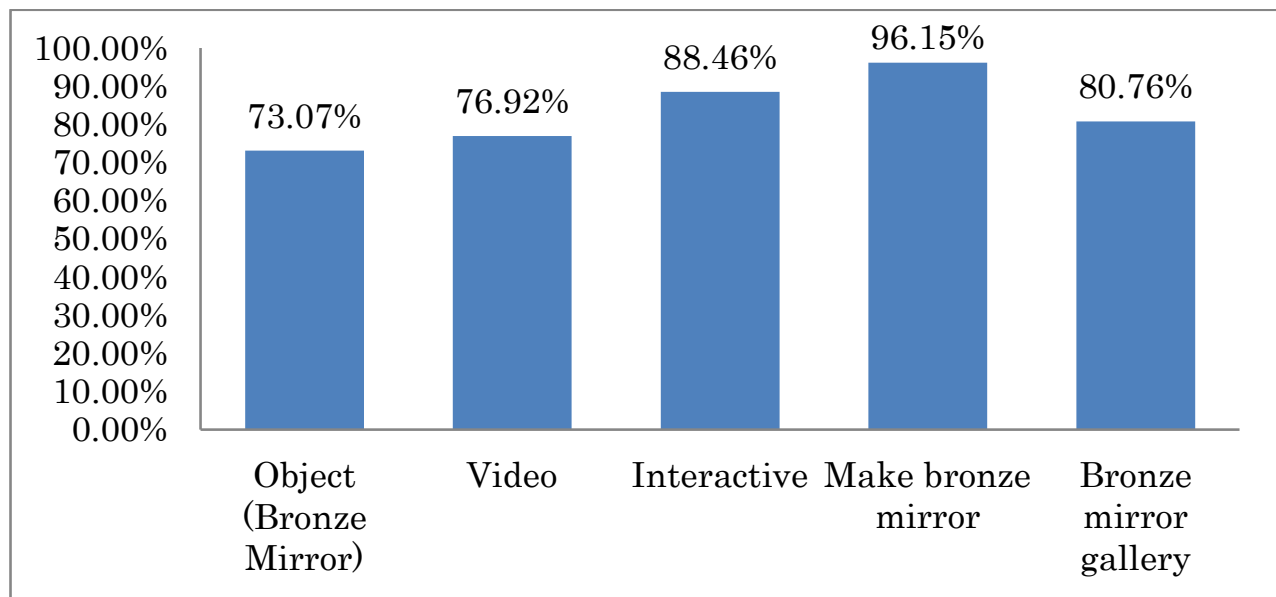

Figure 19. Most liked common items for groups $A$ and $B$ in both the Assemblable walls exhibition and the Hands-on interactive exhibition.

From the questionnaire surveys alone, we can observe that the students liked the experience as a whole, but preferred: the interactive exhibit on the Assemblable walls exhibition, the projection mapping, and making their own bronze mirror, with the latter being the most liked activity overall. As mentioned above, the most used words for describing what they liked about the Hands-on interactive exhibition were related to making by oneself, hinting that it is important to have exhibits which promote creativity.

Regarding the neurofeedback data, the data from the Hands-on interactive exhibition activities was affected in many occasions by the students' sudden movements. For this reason, they were not taken into consideration.

\section{Camp in the past: Yayoi period}

Based on the observations and findings from the experiments, we planned one last experience that would take the most successful characteristics of previous iterations and refine them. As we discovered in the Assemblable walls exhibition, the interactive exhibit was the most effective among the three tested, not only for its interactive component but also because of the character of Himiko. Therefore, we attempted to build around this character, trying to emphasize more on the storytelling aspect that Himiko could contribute.

As for the Hands-on interactive exhibition, two important aspects were examined. First, selecting a digital content platform as a base where other exhibition methods could be built upon, and second including a creative component in the exhibit. However we still included other different methods of exhibition such as video content and handling real objects.

Regarding the space used by the exhibition, finding a middle ground between the walls from the Assemblable walls exhibition and the simplicity of the Hands-on interactive exhibition was the main consideration. For this reason, it was decided to use an existing portable structure from which we could build upon, and that the students would consider attractive. These considerations led us to select a camping tent as the space into which students could enter and experience learning about the Yayoi period with Himiko as their guide. Accordingly, the last iteration was named "Camp in the past: Yayoi period". It was relevant to our purpose of bringing the outreach program to remote places as it aimed to bring the materials from the museum at while also changing the school environment in a way that was easy to transport.

When entering the exhibition, the students encountered a camping tent from the outside (Figure 20). Inside, they would have a layout with the smart projection in front of them as the 
main focus, and a 3D printed mirror replica and a black box on the sides (Figure 21). With this last iteration, our purpose was to inquire about the creation of a physical object as a result of experiencing a digital exhibition. We hypothesized that it would lead the participants to a better appreciation of the object and the experience as a whole.

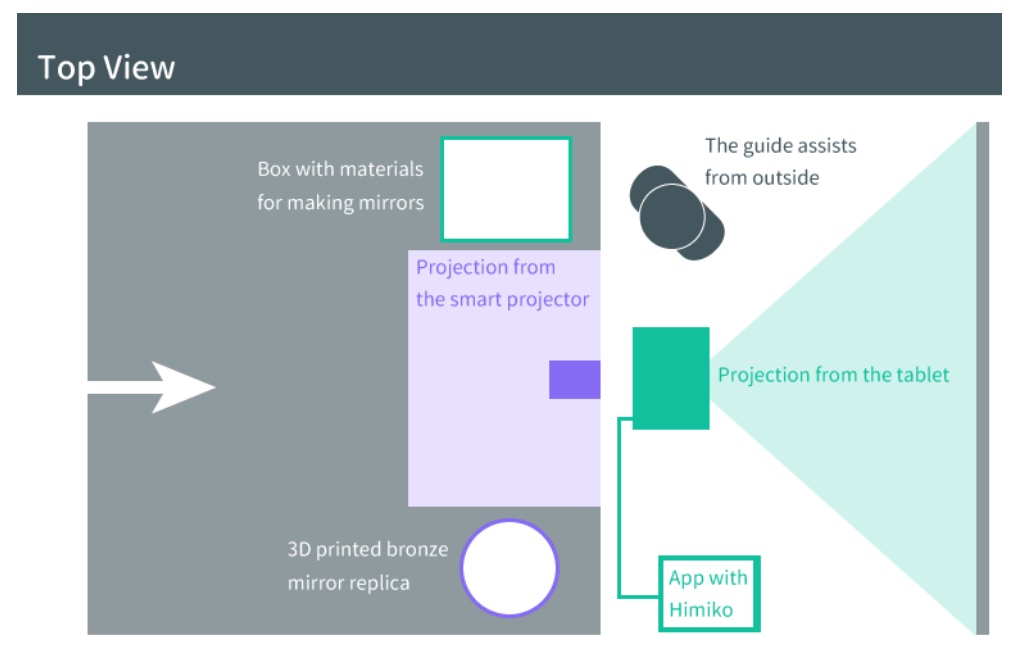

Side View

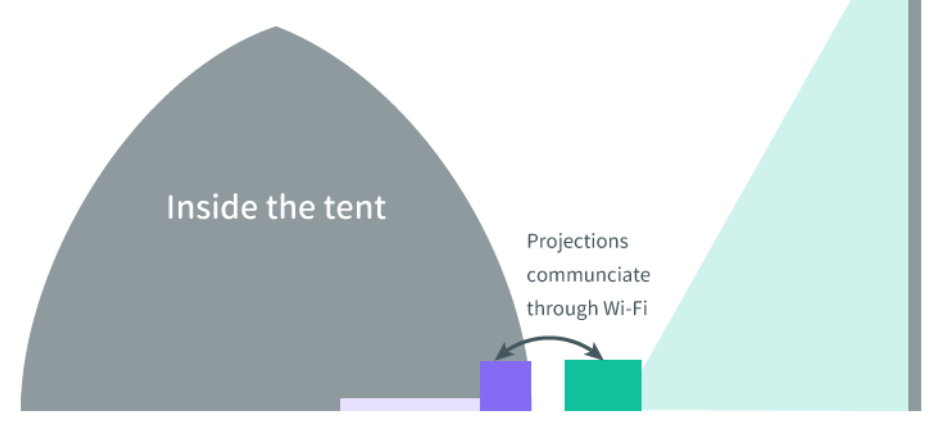

Figure 20. Top and side views of Camp in the past

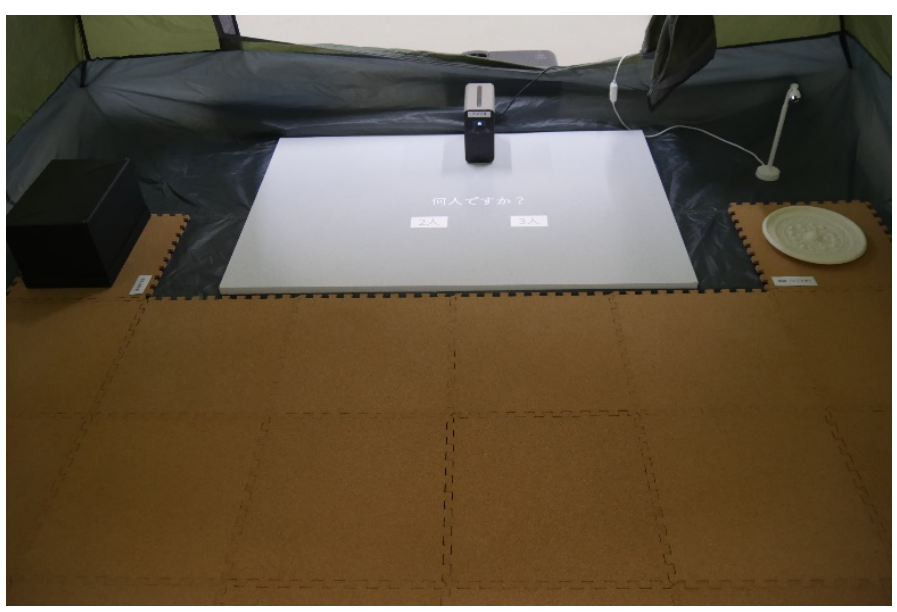

Figure 21. Disposition of the inside of the tent 


\section{Himiko evolved: character and story}

Himiko was redesigned based on characteristics that are attributed to her in current portrayals. However, this time a visual artist was assigned to be in charge of Himiko's design and her movement, this resulted in a more detailed rendition (Figure 22).

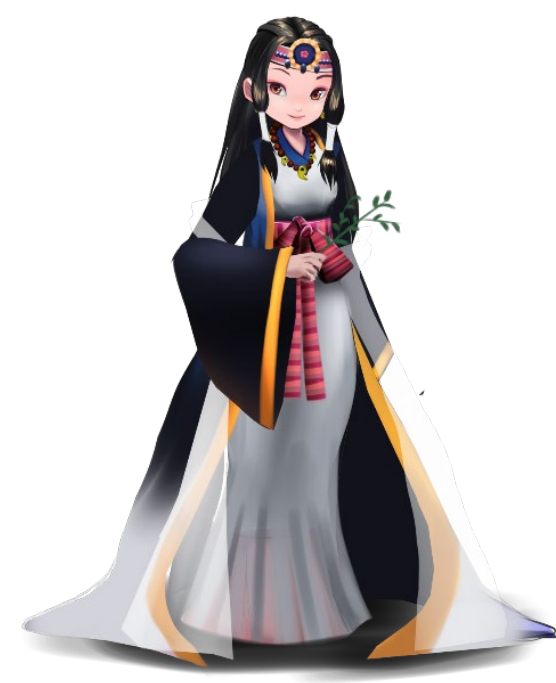

Figure 22. Rendition of Himiko for Camp in the past

Previously, Himiko was only an information provider, no different than a narrated explanation. We learned that the "extras", such as asking Himiko for her age or favourite food, resulted interesting for the students. For which reason, this time Himiko was given a more defined personality and a story in which the students would become participants. This could help the students establish a closer relation to her since she was presented more as a character.

The story planned had to implement some real historical information, but also provide an excuse for the students to perform the activities. The main theme was based on the fact that Himiko had received more than one hundred mirrors from China. In the exhibit storyline, Himiko has lost all her mirrors, thus she asks the visitors to help her collect them again, essentially asking them to make them. This brought a story component to the exhibition that hadn't been explored before in this study. Additionally, Himiko would also give explanations that were previously given by the assistant guide.

Himiko was projected about 2 meters away from the students, while the interaction interface was at reach of the students' hands (Figure 23). The interaction with Himiko was limited to touching buttons in the interface. The usage of voice commands was discarded as it could lead to technical difficulties and it was not as precise and clear as simply touching what the students had in front of them. 


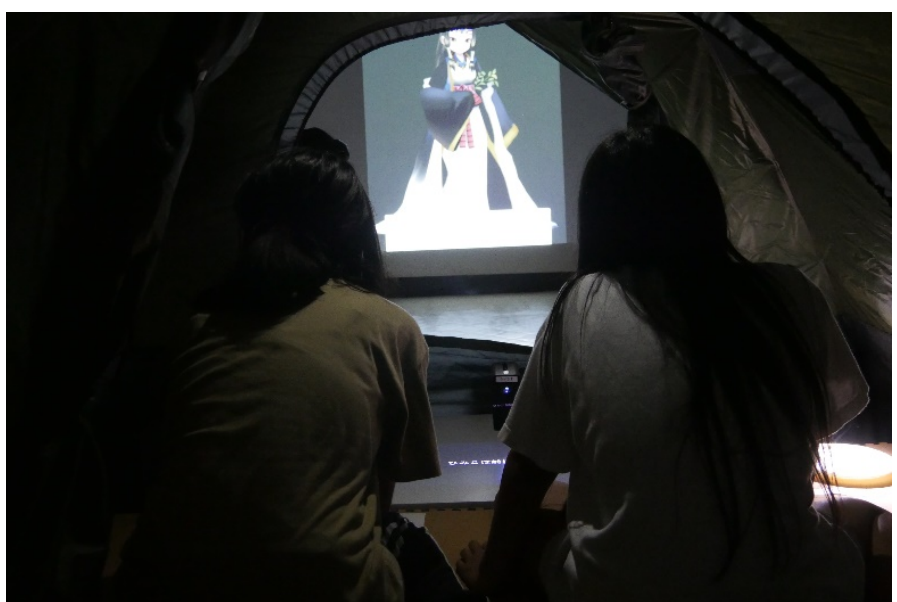

Figure 23. Students looking at Himiko from inside the tent

\section{Analog and digital steps}

In this exhibition Himiko guides the students through a main sequence of activities: an introduction, handling of the bronze mirror replica, watching the projection mapping video, creating their own mirror, and looking at a gallery of the mirrors collected up until now (Figure 24).

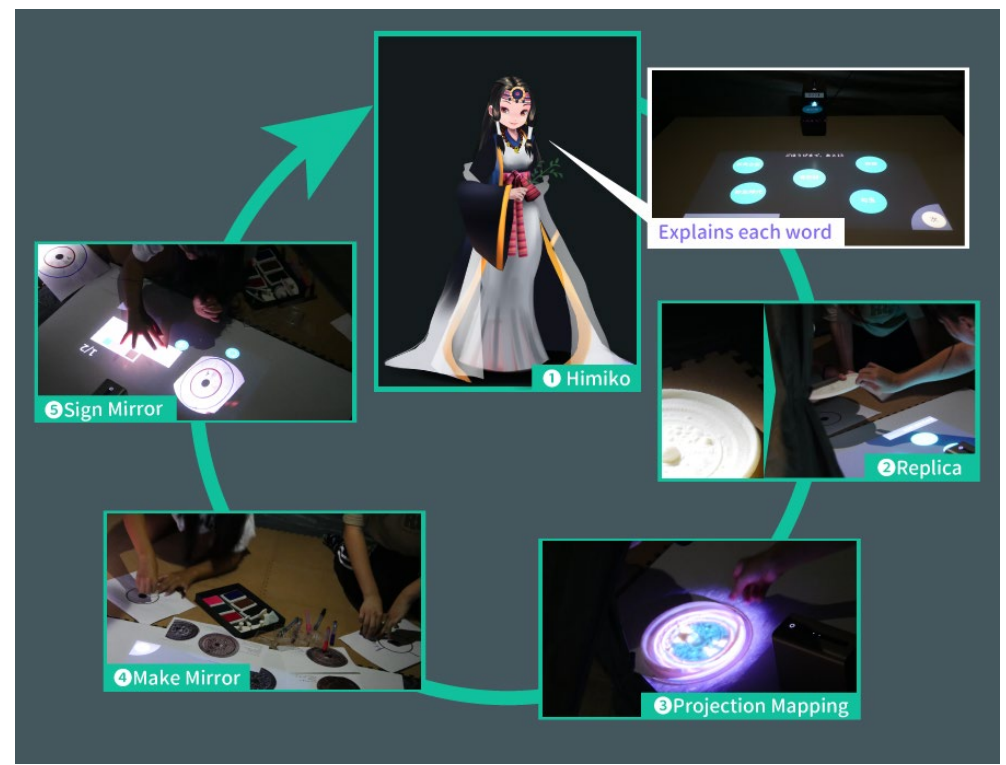

Figure 24. Students looking at Himiko from inside the tent

To enable the students to create their own mirrors, we decided to take a physical approach, since it provided more possibilities for the students to be creative without limiting them to options given in a digital interface. The students received a paper with circular shapes that represented a bronze mirror; they would have to create their own designs on top of them. Their works also needed to have some guidance and basis on real mirrors, so we decided to let them make their own designs by using stamps that had both patterns found in real mirrors and the stylized figures that we used in the projection mapping video. The stamps were made in a 3D printer. Similar to previous work in this study, they had to be modelled in a 3D program and then produced (Figure 25). The stamps were presented to the students along with different ink colours inside a black box that Himiko instructed the students to open at a given time (Figure 26). Inside the box, markers and printings of examples of actual mirrors were also included. 


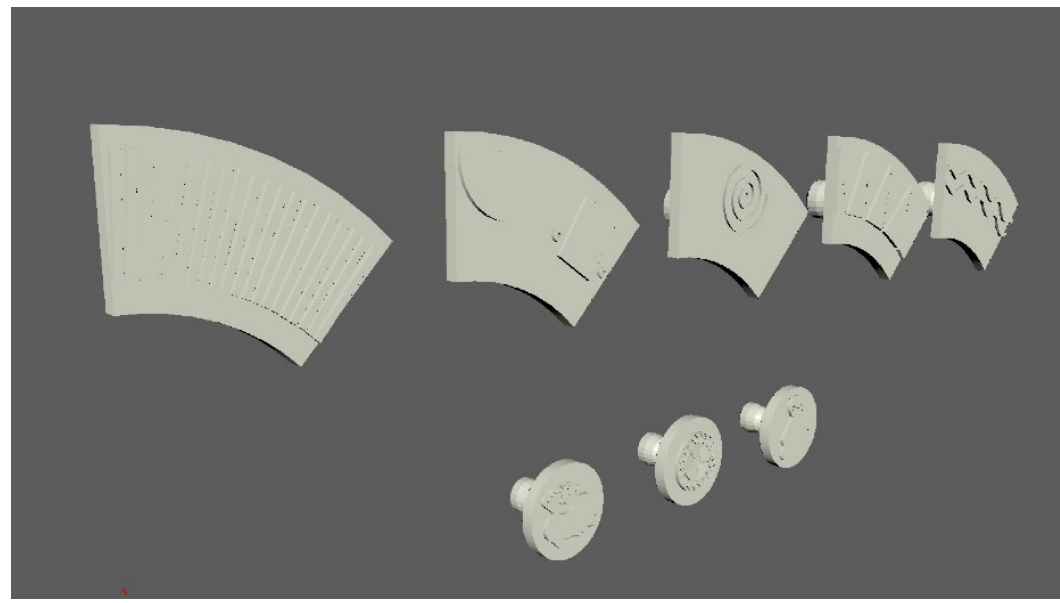

Figure 25. 3D models of the stamps

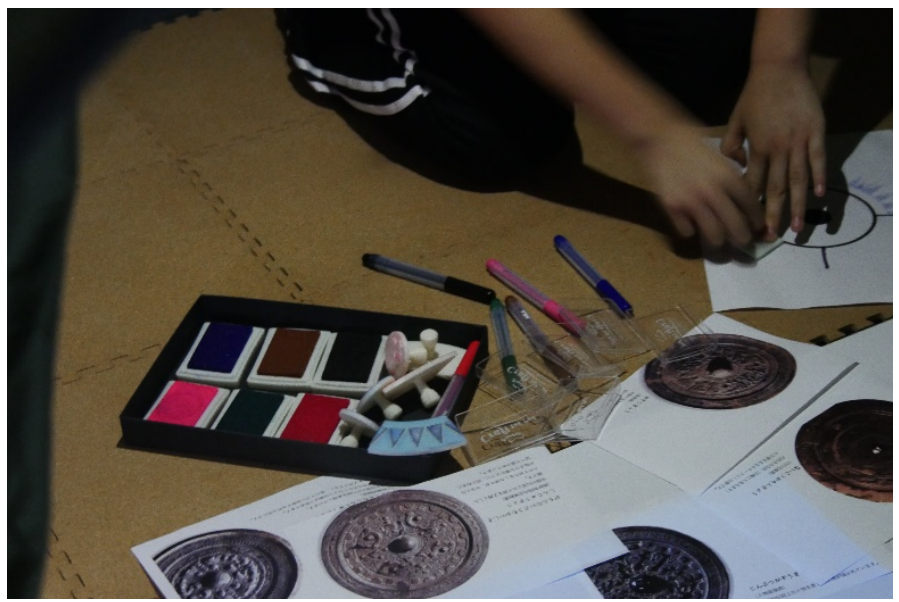

Figure 26. 3D printed stamps

Additionally, in between the activities described above, the students would return each time to a bub where they could press circles containing words from different concepts about the Yayoi period in order to receive explanations from Himiko, in a similar way to the previous interactive exhibit. This time there were no "extra" words except for a divination event. This was only accessible once the students had finished listening to all of the other key-words as a sort of prize. It was planned in this way, because we learned from previous experiments that the students would repeat the divination event while ignoring the other words, nevertheless we still wanted to include it because of its attractiveness.

\section{Experiments and results}

Experiment 03 objectives for Camp in the past: Yayoi Period were as follows:

- Observing the effects of using 3D printed tools in a creative activity.

- Observing how creating an object could impact the memory towards the experience.

- Evaluate the interactive experience in a non-controlled environment that required transporting the materials for the outreach program.

Experiment 03 took place in a controlled environment, with 5 students ranging from fourth to sixth grade of elementary school. 
Two groups of three and two students participated in this experiment; each went through the contents for thirty minutes accompanied by a guide. Additionally, a technician supporter was present for assistance.

In the students' surveys, all the items had perfect scores, this included the experience overall, the environment inside the tent, the Himiko character, the activity with the keywords, the replica handling, the projection mapping and the explanations from the guide. Their written comments were positive too. This was expected, as up until now, the prototype experiences consistently received highly satisfactory results, even with bigger groups.

From observations on site, the students' positive attitude could also be acknowledged; interest towards the creative activity was especially noticeable. Below are the mirror designs made by the students using the stamps and markers (Figure 27).

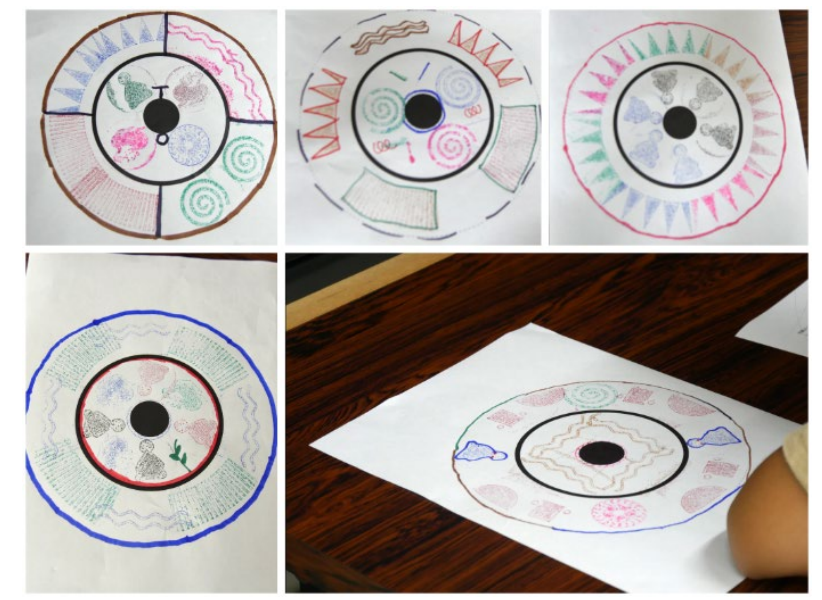

Figure 27. Original bronze mirror designs made by the students in the experiment

One week after the experiment, an online survey for the parents was sent. In this survey, parents were asked about what they had heard about the experiment, and what the children remembered about it. It is relevant to note that one of the respondents did not answer. In a question regarding whether the students mentioned something about the experiment during the last week, three answered that they did, each a different topic: that it was fun as a whole, about Himiko, and the projection mapping.

In a following question regarding whether the participants kept the mirrors, three answered that they still had them. Regarding a question about what the students remembered about the experiment, three mentioned Himiko, and the other mentioned the activity as a whole, as things they haven't experienced up until now. While the number of respondents was small, it can be observed a variety of answers regarding what the students talked about regarding the experiment, and what they remembered towards it. We acknowledge that the experience ought to be tested with a greater group in order to make definitive conclusions regarding how creating an object could impact their memories towards the experience.

\section{Conclusions and proposal for future work}

This research aimed to study different approaches for developing an outreach program by making use of the advantages that digital technologies can offer. The significance of this project is to be able to provide experiences close to what large-scale museums offer in their premises to schools with difficulty accessing them. 
The benefits of digital technologies should be considered in outreach programs, as they are also being implemented progressively in museum exhibitions. It is important, however, to remember what separates the experience of visiting a museum from others: the opportunity to learn from historical artifacts.

On the other hand, different target audiences can be considered. For example, elderly populations who face different difficulties when considering a museum visit, and designing recreational content for them could be considered in future research projects. Furthermore, students with special educational needs or physical disabilities could also be considered as a target audience. The outreach program could become a special support program to bring the museum to people that have different kinds of limitations. The proper application of tools such as the ones demonstrated in this article, could allow museums to further their efforts towards the inclusion of all audiences.

Additionally the design approach presented in this study can be applied to projects in countries other than Japan. As mentioned previously, outreach programs in the form of loan-kits are already implemented in other countries; these could be improved upon by mixing real objects with digital contents that would expand on already established educational resources.

Finally, from the process undergone to develop Camp in the past: Yayoi period, a list of important points is offered which curators at museums willing to start production of outreach programs for schools can take into consideration.

- Make it relevant: The planning of the outreach program content should be based on the school's curriculum in order for it to be significant for the formal education of the students; however, it also has to expand this content with museum knowledge and materials, so the museum can make good use of its resources. The theme of the outreach program must be a result of communication between museum and schools.

- Consider parts for the theme: In order to have a congruent exhibition theme, an era, an object and a character can be selected. The era is directly connected to the content that students are learning at school, while the object establishes a relationship with the museum's collection and what it can provide to the education of students. The character is important as it can serve as a narrative element; a personality that can pull the interest of the students towards the topics.

- Offer variety: Effective content for an outreach program can take many forms, but the most important is to offer a variety of learning activities. Even if all of them can be guided through digital technologies, they must aim to offer access for different learning styles and interests of students.

- Offer a creative activity: It is indispensable to have an emphasis on a creative activity that allows students to make something out of their imagination inspired by historical topics. This activity can then be expanded through digital content-based tools.

- Consider the environment: The above activities should be contained in an environment that changes the space of the school, but takes into consideration limitations related to portability, space and time.

- Consider technologies: The base technology that is implemented must fulfil three conditions: portability for ease of implementation, shareability for the students to have group experiences, and ease of development in order to avoid excessive costs and production time.

- Choosing the staff: A development and event team must be present throughout the project but does not have to be numerous, easing budget concerns. The development team has to consist of at least of a main designer or planner, an artist for visuals and a 
programmer. The event team consists mainly of: a trained guide who can assist the students and lead them through the content; and a technician from the development team who ought to be present in order to address any kind of technical problems, and to assist the guide.

- Make it an event: It is relevant to emphasize that the outreach program can be planned as an event, a special occasion for children to learn in a different way to their usual classroom lessons with the support that a museum can offer, and without the need to travel outside of school. The student as the target user must be considered in all stages of production, as it is for their enjoyment and learning process that all the effort put into making effective contents is made.

The above suggestions are made in hopes of aiding development of future projects that aim to expand museums beyond their premises in innovative ways for bringing their content to schools. We hope the findings and proposals stated in this research can serve the betterment of contents that aid education while offering enjoyable experiences.

\section{References}

1. Aoki, Y. (1997). Hakubutsukan eizo tenjiron: shichokaku media o meguru. Tokyo: Yuzankaku (in Japanese).

2. Australian Museum (n.d.). Museum in a Box. Retrieved March 25, 2019, from https://australianmuseum.net.au/learn/teachers/museum-box/

3. Caulton, T. (2004). Hands-on exbibitions managing interactive museums and science centres. London: Routledge.

4. Demos, J. N. (2005). Getting started with neurofeedback. New York: W.W. Norton.

5. Geller, T. (2006). Interactive tabletop exhibits in museums and galleries. IEEE Computer Graphics and Applications, 26(5), 6-11.

6. McLean, K. (2013). Planning for people in museum exhibitions. Washington, D.C.: Association of Science-Technology Centers.

7. Moreno Quiroga, J., Izumoto, C., Kaneko, K., Yonemoto, S., \& Kim, D., (2016). Planning and Developing a Museum Outreach Program for Schools. International Journal of Asia Digital Art \& Design, 20(2), 51-59.

8. Museum of Cycladic art (n.d.). Museum Kits. Retrieved March 25, 2019, from https://cycladic.gr/en/page/mousioskeues

9. Shaku, C. (2018). Report of the Exbibition and Meeting for "Museum kits for the schools". http://doi.org/10.20643/00001300 (in Japanese).

10. The Japan Society for Exhibition studies (Ed.) (2010). Tenjiron -bakubutsukan no tenji o tsukuruTokyo: Yuzankaku (in Japanese).

11. Wellburn, E., \& Eibd, B. J. (2016). Multiple Learning Roles in a Connected Age. In Veletsianos, G (Ed.), Emergence and Innovation in Digital Learning (pp. 65-80). Edmonton: AU Press.

12. Yutaka, M. (2007). Cho bijutsukan kakumei: Kanazawa 21 seiki bijutsukan no chosen. Tokyo: Kadokawa Shoten (in Japanese). 